\title{
New FDA Guidance on General Clinical Trial Conduct in the Era of COVID-19
}

\author{
J. Rick Turner ${ }^{1}$
}

Received: 1 May 2020 / Accepted: 1 May 2020 / Published online: 9 May 2020

(C) The Drug Information Association, Inc 2020

Readers will be well aware of the Coronavirus Disease 2019 (COVID-19) pandemic that is sweeping the globe, both from media coverage and recent publications in the literature [1-6]. On January 31, 2020 the US Secretary of Health and Human Services determined that a public health emergency existed nationwide in the USA [7]. Since then, the US Food and Drug Administration (FDA) has been engaged in many efforts to combat this disease, including the release of several guidances, each of which is available for download at www.FDA.gov.

Some guidances focus on topics specifically addressing diagnosis and treatment of COVID-19, e.g., policy for diagnostic tests for COVID-19 [8] and enforcement policy for ventilators and accessories and other respiratory devices during the COVID-19 public health emergency [9]. The focus of this Editorial is the guidance entitled "FDA Guidance on Conduct of Clinical Trials of Medical Products during COVID-19 Pandemic: Guidance for Industry, Investigators, and Institutional Review Boards." [10] FDA recognizes that the COVID-19 pandemic "may impact the conduct of [all] clinical trials of medical products. Challenges may arise, for example, from quarantines, site closures, travel limitations, interruptions to the supply chain for the investigational product, or other considerations if site personnel or trial subjects become infected with COVID-19" [10].

\section{Releasing Guidances in Final Form}

FDA guidances are typically first released in draft form, followed by a period of time (often 60 days) during which stakeholders can submit comments to a related FDA docket. These comments are then considered during the preparation of the final guidance. Given current exigencies, the clinical

J. Rick Turner

j.rick.turner123@outlook.com

1 Buies Creek, USA trials guidance (as were others) was released in final form and implemented immediately. That said and as is true for all guidances, including those that have gone through the typical process to become final-public comments may be submitted at any time to the respective docket [11] in accordance with FDA's good guidance practices.

\section{Key Messages in the Guidance on Conduct of Clinical Trials of Medical Products During the COVID-19 Pandemic}

Clinical trials are governed by study protocols. As Chow and Chang [12] observed, the study protocol is "the most important document in clinical trials, since it ensures the quality and integrity of the clinical investigation in terms of its planning, execution, conduct, and the analysis of the data." Protocols, typically reviewed by Institutional Review Boards (IRBs)/Independent Ethics Committees (IECs), are comprehensive plans of action that contain information concerning the goals of the study, and details of participant recruitment, safety monitoring, and all aspects of study design, methodology, and statistical analysis. As noted in the guidance, "changes in a protocol are typically not implemented before review and approval by the IRB/IEC and in some cases, by FDA" [10]. However, these are not typical times, hence the release of this guidance.

The guidance acknowledges that protocol modifications may be required, and that unavoidable protocol deviations due to the ramifications of COVID-19 may occur. Accordingly, it outlines general strategies to help sponsors ensure the safety of trial participants (the paramount consideration), maintain compliance with good clinical practice, and minimize risks to trial integrity.

Key take-home messages for investigators and sponsors include: (1) keep study participants informed of all changes to a trial's conduct, including continuation of recruitment, use of the investigational product for participants already in 
the trial, warranted changes in monitoring, and even potential discontinuation of participation in the trial; (2) thoroughly document all changes and their effects, including but not limited to how restrictions related to COVID-19 led to changes in study conduct and their duration, and what protocol-specified information may be missing in the overall dataset; and (3) engage with IRBs/IECs as early as possible when urgent or emergent changes to the protocol are anticipated. With regard to the second point, missing information may be related to modified study visit schedules, missed visits, or participant discontinuations. Documentation of specific information explaining the basis for missing data should be summarized in the trial's Clinical Study Report as it will be helpful to the FDA.

With respect to participant safety, as some participants may not be able to visit investigational sites for protocolspecified visits, consideration should be given to potential alternative methodologies for safety assessment, e.g., phone calls, virtual visits, and alternative locations for assessments, including local labs and imaging centers, and whether participants' safety can be assured by these alternatives. With respect to efficacy assessments, FDA's recommendation is for sponsors to consult with the appropriate review division regarding protocol modifications for the collection of efficacy endpoints, such as employment of virtual assessments, delays in assessments, and alternate collection methods for research-specific specimens, if feasible. Additionally, if protocol changes will cause amended data management and/or statistical analysis plans, sponsors should similarly consult with the appropriate review division.

\section{Concluding Comment}

The guidance ends with the following message:

Robust efforts by sponsors, investigators, and IRBs/ IECs to maintain the safety of trial participants and study data integrity are expected, and such efforts should be documented ... FDA recognizes that protocol modifications may be required, including unavoidable protocol deviations due to COVID-19 illness and/ or COVID-19 control measures. Efforts to minimize impacts on trial integrity, and to document the reasons for protocol deviations, will be important.

Everyone involved in clinical trial conduct, analysis, and reporting at this time is strongly encouraged to read the guidance.

\author{
J. Rick Turner, PhD, DSc, FAHA, FCP \\ Editor Emeritus
}

\section{References}

1. Driggin E, Madhavan MV, Bikdeli B, Chuich T, Laracy J, BondiZoccai G, et al. Cardiovascular considerations for patients, health care workers, and health systems during the coronavirus disease (COVID-19) pandemic. J Am Coll Cardiol. 2019. https://doi. org/10.1016/j.jacc.2020.03.031.

2. Wang LS, Wang YR, Ye DW, Liu QQ. A review of the 2019 Novel Coronavirus (COVID-19) based on current evidence. Int J Antimicrob Agents. 2020. https://doi.org/10.1016/j.ijantimica g.2020.105948.

3. Greenland JR, Michelow MD, Wang L, London MJ. COVID-19 infection: implications for perioperative and critical care physicians. Anesthesiology. 2020. https://doi.org/10.1097/ALN.00000 00000003303.

4. Ramanathan K, Antognini D, Combes A, Paden M, Zakhary B, Ogino $\mathrm{M}$, et al. Planning and provision of ECMO services for severe ARDS during the COVID-19 pandemic and other outbreaks of emerging infectious diseases. Lancet Respir Med. 2020. https://doi.org/10.1016/S2213-2600(20)30121-1.

5. Perico L, Benigni A, Remuzzi G. Should COVID-19 concern nephrologists? Why and to what extent? The emerging impasse of angiotensin blockade. Nephron. 2020;23:1-9.

6. Giudicessi JR, Noseworthy PA, Friedman PA, Ackerman MJ. Urgent guidance for navigating and circumventing the QTc prolonging and torsadogenic potential of possible pharmacotherapies for COVID-19. Mayo Clin Proc. 2020. https://doi.org/10.1016/j. mayocp.2020.03.024.

7. U.S. Secretary of Health and Human Services. Determination that a Public Health Emergency Exists. https://www.phe.gov/emerg ency/news/healthactions/phe/Pages/2019-nCoV.aspx. Accessed April 8, 2020.

8. FDA. Policy for Diagnostic Tests for Coronavirus Disease-2019 during the Public Health Emergency: Immediately in Effect Guidance for Clinical Laboratories, Commercial Manufacturers, and Food and Drug Administration Staff. https://www.fda.gov/media /135659/download. Accessed 8 Apr 2020.

9. FDA. Enforcement Policy for Ventilators and Accessories and Other Respiratory Devices During the Coronavirus Disease 2019 (COVID-19) Public Health Emergency: Guidance for Industry and Food and Drug Administration Staff. https://www.fda.gov/media /136318/download. Accessed 8 Apr 2020.

10. FDA. FDA Guidance on Conduct of Clinical Trials of Medical Products during COVID-19 Pandemic: Guidance for Industry, Investigators, and Institutional Review Boards. https://www.fda. gov/media/136238/download. Accessed 8 Apr 2020.

11. FDA Docket. FDA Guidance on Conduct of Clinical Trials of Medical Products during COVID-19 Pandemic: Guidance for Industry, Investigators, and Institutional Review Boards. https:// www.fda.gov/regulatory-information/search-fda-guidance-docum ents/fda-guidance-conduct-clinical-trials-medical-products-durin g-covid-19-pandemic. Accessed 8 Apr 2020.

12. Chow S-C, Chang M. Adaptive design methods in clinical trials. Boca Raton: Chapman \& Hall; 2007. 